\title{
Iron(II) and Iron(III) Spin Crossover: Toward an Optimal Density Functional
}

\author{
Sørensen Siig, Oliver ; Planeta Kepp, Kasper
}

Published in:

Journal of Physical Chemistry Part A: Molecules, Spectroscopy, Kinetics, Environment and General Theory

Link to article, DOI:

10.1021/acs.jpca.8b02027

Publication date:

2018

Document Version

Peer reviewed version

Link back to DTU Orbit

Citation (APA):

Sørensen Siig, O., \& Planeta Kepp, K. (2018). Iron(II) and Iron(III) Spin Crossover: Toward an Optimal Density Functional. Journal of Physical Chemistry Part A: Molecules, Spectroscopy, Kinetics, Environment and General Theory, 122(16), 4208-4217. https://doi.org/10.1021/acs.jpca.8b02027

\section{General rights}

Copyright and moral rights for the publications made accessible in the public portal are retained by the authors and/or other copyright owners and it is a condition of accessing publications that users recognise and abide by the legal requirements associated with these rights.

- Users may download and print one copy of any publication from the public portal for the purpose of private study or research.

- You may not further distribute the material or use it for any profit-making activity or commercial gain

- You may freely distribute the URL identifying the publication in the public portal 
Subscriber access provided by DTU Library

A: Molecular Structure, Quantum Chemistry, and General Theory

Fe(II) and Fe(III) Spin Crossover: Towards an Optimal Density Functional

Oliver Sørensen Siig, and Kasper P. Kepp

J. Phys. Chem. A, Just Accepted Manuscript • DOI: 10.1021/acs.jpca.8b02027 • Publication Date (Web): 09 Apr 2018

Downloaded from http://pubs.acs.org on April 10, 2018

\section{Just Accepted}

"Just Accepted" manuscripts have been peer-reviewed and accepted for publication. They are posted online prior to technical editing, formatting for publication and author proofing. The American Chemical Society provides "Just Accepted" as a service to the research community to expedite the dissemination of scientific material as soon as possible after acceptance. "Just Accepted" manuscripts appear in full in PDF format accompanied by an HTML abstract. "Just Accepted" manuscripts have been fully peer reviewed, but should not be considered the official version of record. They are citable by the Digital Object Identifier (DOI®). "Just Accepted" is an optional service offered to authors. Therefore, the "Just Accepted" Web site may not include all articles that will be published in the journal. After a manuscript is technically edited and formatted, it will be removed from the "Just Accepted" Web site and published as an ASAP article. Note that technical editing may introduce minor changes to the manuscript text and/or graphics which could affect content, and all legal disclaimers and ethical guidelines that apply to the journal pertain. ACS cannot be held responsible for errors or consequences arising from the use of information contained in these "Just Accepted" manuscripts. 


\title{
$\mathrm{Fe}(\mathrm{II})$ and $\mathrm{Fe}(\mathrm{III})$ Spin Crossover: Towards an Optimal Density Functional
}

\author{
Oliver S. Siig and Kasper P. Kepp*,
}

Technical University of Denmark, DTU Chemistry, Building 206, 2800 Kgs. Lyngby, DK Denmark.

* Corresponding Author. Phone: +045 452524 09. E-mail: kpj@kemi.dtu.dk

\begin{abstract}
Spin crossover (SCO) plays a major role in biochemistry, catalysis, materials, and emerging technologies such as molecular electronics and sensors, and thus accurate prediction and design of SCO systems is of high priority. However, the main tool for this purpose, density functional theory (DFT), is very sensitive to applied methodology. The most abundant SCO systems are $\mathrm{Fe}(\mathrm{II})$ and $\mathrm{Fe}(\mathrm{III})$ systems. Even with average good agreement, a functional may be significantly more accurate for $\mathrm{Fe}(\mathrm{II})$ or $\mathrm{Fe}(\mathrm{III})$ systems, preventing balanced study of SCO candidates of both types. The present work investigates DFT's performance for well-known Fe(II) and Fe(III) SCO complexes, using various design types and customized versions of GGA, hybrid, meta-GGA, meta-hybrid, double-hybrid, and long-range-corrected hybrid functionals. We explore the limits of DFT performance and identify proficient Fe(II)-Fe(III)-balanced functionals. We identify and quantify remarkable differences in the DFT description of $\mathrm{Fe}(\mathrm{II})$ and $\mathrm{Fe}(\mathrm{III})$ systems. Most functionals become more accurate once Hartree-Fock exchange is adjusted to $10-17 \%$, regardless of the type of functionals involved. However this typically introduces a clear Fe(II)-Fe(III) bias. The most accurate functionals measured by mean absolute errors $<10 \mathrm{~kJ} / \mathrm{mol}$ are CAMB3LYP17, B3LYP*, and B97-15 with 15-17\% Hartree-Fock exchange, closely followed by
\end{abstract}


CAMB3LYP and CAMB3LYP-15, OPBE, rPBE-10, and B3P86-15. While GGA functionals display a small $\mathrm{Fe}(\mathrm{II})-\mathrm{Fe}(\mathrm{III})$ bias, they are generally inaccurate, except the $\mathrm{O}$ exchange functional. Hybrid functionals (including B2PLYP double hybrids and meta hybrids) tend to favor HS too much in $\mathrm{Fe}(\mathrm{II})$ vs. Fe(III), which is important in many studies where the oxidation state of iron can vary, e.g. rational SCO design and studies of catalytic processes involving iron. The only functional with a combined bias $<5 \mathrm{~kJ} / \mathrm{mol}$ and a decent MAE $(15 \mathrm{~kJ} / \mathrm{mol})$ is our customized PBE0-12 functional. Alternatively one has to sacrifice Fe(II)-Fe(III) balance to use the best functionals for each group separately. We also investigated the precision (measured as the standard deviation of errors) and show that the target accuracy for iron SCO is $10 \mathrm{~kJ} / \mathrm{mol}$ for accuracy and $5 \mathrm{~kJ} / \mathrm{mol}$ for precision, and DFT is probably not going to break this limit in the near future. Importantly, all four types of functional behavior (accurate/precise, accurate/imprecise, inaccurate/precise, inaccurate/imprecise) are observed. More generally, our work illustrates the importance not only of overall accuracy but also balanced accuracy for systems likely to occur in context. 


\section{Introduction.}

Spin crossover $(\mathrm{SCO})$ is a fundamental quantum mechanical process occurring in some molecular systems whereby two electronic states with different net spin, high-spin (HS) and lowspin (LS), interconvert upon perturbation, e.g. temperature or pressure ${ }^{1-8}$. SCO requires that the free energy difference between the two electronic spin states is close to zero under the conditions of interest ${ }^{2,9,10}$ :

$$
\Delta G_{\mathrm{SCO}}=\Delta H_{\mathrm{SCO}}-T \Delta S_{\mathrm{SCO}} \approx 0
$$

The reaction enthalpy $\Delta H_{\mathrm{SCO}}$ largely arises from the electronic changes of the first coordination sphere during SCO and typically favors LS, whereas the entropy of the process $\Delta S_{\mathrm{SCO}}$ largely arises from changes in the geometries during SCO and typically favors HS because of the longer and weaker metal-ligand bonds due to occupation of the $\mathrm{e}_{\mathrm{g}}$ orbials pointing towards the ligands 9,11 . Many SCO systems have been designed during the past many decades, and some have had their free energy decomposed into $\Delta S_{\mathrm{SCO}}$ and $\Delta H_{\mathrm{SCO}}$ contributions ${ }^{2,12-14}$. Because HS states possess more entropic metal-ligand bonds, the enthalpy-entropy compensation is remarkably strong ${ }^{12}$ and largely responsible for the thermally induced transition to HS that can be observed experimentally, as the T $\Delta \mathrm{S}$ term begins to favor the HS state ${ }^{2}$.

SCO is a fundamentally important feature of life, as it is required for biological control over the triplet $\mathrm{O}_{2}$ in the Earth's atmosphere ${ }^{15,16}$. SCO is also important to various technological applications such as molecular magnets, sensors, molecular electronics and transition-metalbased catalysis $^{3,17-21}$. Iron is the most common central metal ion in current SCO systems. The balance between the central metal ion and the ligand field together enables SCO as both central ion and ligand has systematic spin state preferences ${ }^{22}$. The spectrochemical series ${ }^{23-25}$ gives information about this via the (vertical) energy difference between the orbital levels involved in 
SCO (in $\mathrm{O}_{\mathrm{h}}$ symmetry the splitting $\Delta_{\mathrm{o}}$ of the $\mathrm{e}_{\mathrm{g}}$ and $\mathrm{t}_{2 \mathrm{~g}}$ levels). The more relevant series for rationalizing and predicting SCO is a thermochemical series of spin state propensities ${ }^{26}$, which corrects the spectrochemical series by accounting for the substantial contributions from geometric relaxation, spin pairing, and entropy and vibrational effects ${ }^{12,26}$. From such ligandmetal considerations it can be seen that iron with nitrogen donor ligands is a hotspot for $\mathrm{SCO}^{26}$. 6-coordinate iron(II) complexes with nitrogen donor ligands are $\operatorname{archetypical}^{5}$, with heme being the natural reference benchmark of this type whose SCO plays a fundamental role in the oxygen management of $\operatorname{life}^{27}$.

Density functional theory (DFT) is well suited to study SCO systems, as the electron correlation can be described accurately at a relatively modest computational $\operatorname{cost}^{28,29}$. However, the precise relative energy of HS and LS states is hard to obtain, because this requires a balanced treatment of Fermi and Coulomb correlation ${ }^{9}$. Different density functionals produce very different HS-LS energy gaps as has been discussed in detail ${ }^{9,12,14,26,30-41}$. Because the exchange integrals of the Hartree-Fock (HF) treatment only account for Fermi correlation, they explicitly favor HS. Accordingly, the amount of HF exchange included in a hybrid functional dominates

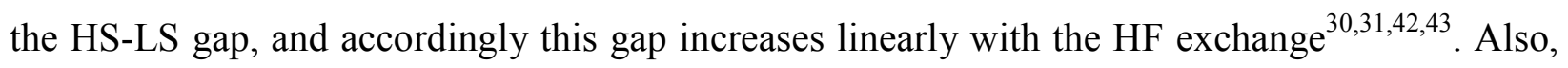
the inclusion of gradient terms in meta functionals has been found to affect the HS-LS gap ${ }^{26,44}$.

The major concern in DFT which also specifically relates to SCO is the predictive value of a given functional once applied outside its parameterization range, i.e. "universality"45-47 . We have previously observed ${ }^{12}$ that the ferric Fe(III) and ferrous Fe(II) systems are not described equally well by a given functional, and this effect is very significant vs. the noise in the methodology. From the SCOFE30 database ${ }^{12}$, it can be seen that Fe(III) SCO systems tend to have experimental $\Delta H_{\mathrm{SCO}}$ about $10 \mathrm{~kJ} / \mathrm{mol}$ smaller than Fe(II) systems, and correspondingly also, due to the strong enthalpy-entropy compensation ${ }^{12}$, the experimental $\Delta S_{\mathrm{SCO}}$ is smaller by perhaps 
$30 \mathrm{~J} / \mathrm{molK}$. Because of the diverse ligands of this data set, these effects are averages with large variations depending on the exact ligand field, but the trend is clear. The differential ligand field stabilization energy and spin pairing effects are the same $(10 / 5$ and a change of $2 P)$. This explains why the difference is relatively subtle.

Unfortunately, these differences pose a challenge to DFT: Thus, B3LYP*-D3 performs best in a test once all physical effects (zero point energy, vibrational entropy, relativistic corrections, dispersion) are included before comparison to experimental $\Delta H_{\mathrm{SCO}}$, but closer inspection shows that this comes at a price of producing too much high-spin in Fe(II) systems and too much LS in Fe(III) systems ${ }^{12}$. The failure arises mainly for the hybrid functionals, as they tend to not only favor HS, but favor HS too much in Fe(II) compared to Fe(III). In the following we refer to this as the "Fe(II)-Fe(III) bias". This bias, upon reinspection of previous results, easily passes $20 \mathrm{~kJ} / \mathrm{mol}^{12}$. This bias has so far been overlooked and has not previously, to our knowledge, been described, although Friesner et al. have studied d-configuration-dependent energies with DFT and addressed some related challenges ${ }^{48}$.

Our computations in this paper show that, in the search for a proficient density functional description of spin states of iron of major importance in many catalytic processes, the Fe(II)Fe(III) bias produces an important obstacle. Thus, we decided to explore this bias, and investigate how far we can get with modern DFT towards optimal SCO performance, while considering both accuracy, precision, and the Fe(II)-Fe(III) bias. In this search, we study a range of different classes of density functionals, including GGAs, hybrids, meta GGAs, meta hybrids, dopuble hybrids, and range-separated hybrids, and also investigate customized versions to identify the limits of accuracy and precision when applying DFT to the study of iron spin states.

\section{Methods.}


All computations were performed using the Turbomole software, version $7.0^{49}$. The electron densities and energies were converged to $10^{-6}$ a.u., and the resolution of identify approximation was used to speed up the calculations ${ }^{50,51}$.

In order to analyze Fe(II) and Fe(III) systems fairly, we used a balanced data set shown in Figure 1, consisting of five Fe(II) SCO systems and five Fe(III) SCO systems. The five Fe(II) systems are 1: $\left[\mathrm{Fe}(\text { papth })_{2}\right]^{2+}$ (papth $=$ bis(2-(2-pyridylamino)-4-(2-pyridyl)thiazole $\left.)^{52}\right) ; 2$ : $\left[\mathrm{Fe}(\operatorname{tacn})_{2}\right]^{2+}\left(\operatorname{tacn}=1,4,7-\mathrm{Triazacyclononane}^{53}\right) ; \quad 3:\left[\mathrm{Fe}(\text { pyimH })_{3}\right]^{2+} \quad\left(\right.$ pyimH $=2-\left(2^{\prime}-\right.$ pyridyl)imidazole $\left.{ }^{53}\right) ; 4:[\mathrm{Fe}(\operatorname{tpchxn})]^{2+}\left(\operatorname{tpchxn}=\mathrm{N}, \mathrm{N}, \mathrm{N}^{\prime}, \mathrm{N}^{\prime}\right.$-tetrakis(2-pyridylmethyl)-1 $R, 2 R-$ cyclohexanediamine $\left.^{54}\right)$; and the classic 5: $\left[\mathrm{Fe}(\text { phen })_{2}(\mathrm{NCS})_{2}\right]\left(\right.$ phen $=1,10$-phenanthroline $\left.{ }^{55}\right)$. The five $\mathrm{Fe}(\mathrm{III})$ systems studied are: 6: $\left[\mathrm{Fe}(\mathrm{acac})_{2} \text { trien }\right]^{+} \quad($ acac $=$ acetyl-acetonatetriethylenetetramine $\left.{ }^{56}\right) ; 7:\left[\mathrm{Fe}(\text { bzac })_{2} \text { trien }\right]^{+}\left(\right.$bzac $=$benzoyl-acetonate-triethylenetetramine $\left.{ }^{57}\right)$; 8: $\left[\mathrm{Fe}(\mathrm{bzacCl})_{2} \text { trien }\right]^{+},{ }^{57}$ 9: $\mathrm{Fe}(\mathrm{tfac})_{2}$ trien $]^{+}$(trifluoroacetyl-acetonate-riethylenetetramine ${ }^{57}$ ); and 10: $\left[\mathrm{Fe}(3-\mathrm{MeO}-\mathrm{salenEt})_{2}\right]^{+} \quad(3-\mathrm{MeO}-\mathrm{salenEt} \quad=\quad 3$-methoxysalicylaldehyde-Nethylethylenediamine $^{58}$ ). The geometries were optimized as previously described ${ }^{12}$ using the BP86 $6^{59,60}$ functional known to give accurate geometries for transition metal systems and the def2-SVP basis set ${ }^{61}$ including the Cosmo solvation model ${ }^{62,63}$. The Cosmo radii for all atoms were the optimized default values of Turbomole, and $2.0 \AA$ was used for iron. This protocol routinely provides excellent geometries for first row transition metal complexes with typical errors in metal-ligand bond lengths of $0.02-0.03 \AA^{64}$.

The entropy, in particular the vibrational entropy, plays an important role in determining the spin crossover tendency, which is given by the free energy in Equation (1). This entropy is larger for the HS state with the longer and weaker metal-ligand bonds. The entropy can be modeled using the molecular vibration state function of the low-spin and high-spin states after calculating the vibrational frequencies in both states. Thus, it is not very sensitive to the choice 
of functional and is well modeled e.g. by a GGA functional such as BP86 ${ }^{12}$. The main challenge in modeling SCO systems with DFT thus lies in the choice of functional used to computed $\Delta \mathrm{H}_{\mathrm{SCO}}$, and we focus our benchmark on the ability of DFT to reproduce this observable.

For assessing the energy difference between HS and LS states, energies for all functionals were converged using the fully polarized def2-TZVPP basis set ${ }^{61}$; this basis set performed accurately in previous benchmarks against experimental SCO enthalpies ${ }^{12,33}$. In the present work, a range of functionals were studied to investigate the Fe(II)-Fe(III) bias. Since some functionals were already studied in a previous benchmark ${ }^{12}$, these were excluded from the present study except the three best functionals ${ }^{12,31,33}$ : the double-hybrid B2PLYP which includes both MP2 correlation energy and HF exchange corrections to the correlation and exchange functionals ${ }^{65}$, the meta hybrid TPSSh ${ }^{66,67}$ with $10 \%$ HF exchange, and B3LYP*30 which is a $15 \%$ version of B3LYP ${ }^{68-70}$, the latter two in their D3 corrected versions ${ }^{71}$. The TPSS ${ }^{66}$ functional as the direct non-hybrid counterpart of TPSSh was also included for strict comparison.

In addition, we studied the long range-corrected hybrid functional CAMB3LYP ${ }^{72}$, which separates the exchange interaction into long- and short-range parts; M06 and M06-2X, which are meta hybrids with $27 \%$ and $54 \%$ HF exchange, respectively ${ }^{73}$; the local M06L functional ${ }^{74}$; the KT1 and KT2 functionals by Keal and Tozer ${ }^{75}$, which are GGA type functionals developed specifically for good performance for NMR parameters (KT1 obeys the uniform gas constraint; KT2 is fitted); $\mathrm{PW} 91-\mathrm{PW}^{76}$; the two main revised versions of $\mathrm{PBE}^{77}, \mathrm{revPBE}^{78}$ and $\mathrm{rPBE}^{79}$; OPBE and OLYP using Handy and Cohen's optimized exchange functional ${ }^{80}$ with the $\mathrm{PBE}^{77}$ or $\mathrm{LYP}^{69}$ correlation functionals; B-VWN ${ }^{59,81}$; B3P86 $6^{60,68}$; and $\mathrm{PBEH}-3 \mathrm{C}^{82}$. 


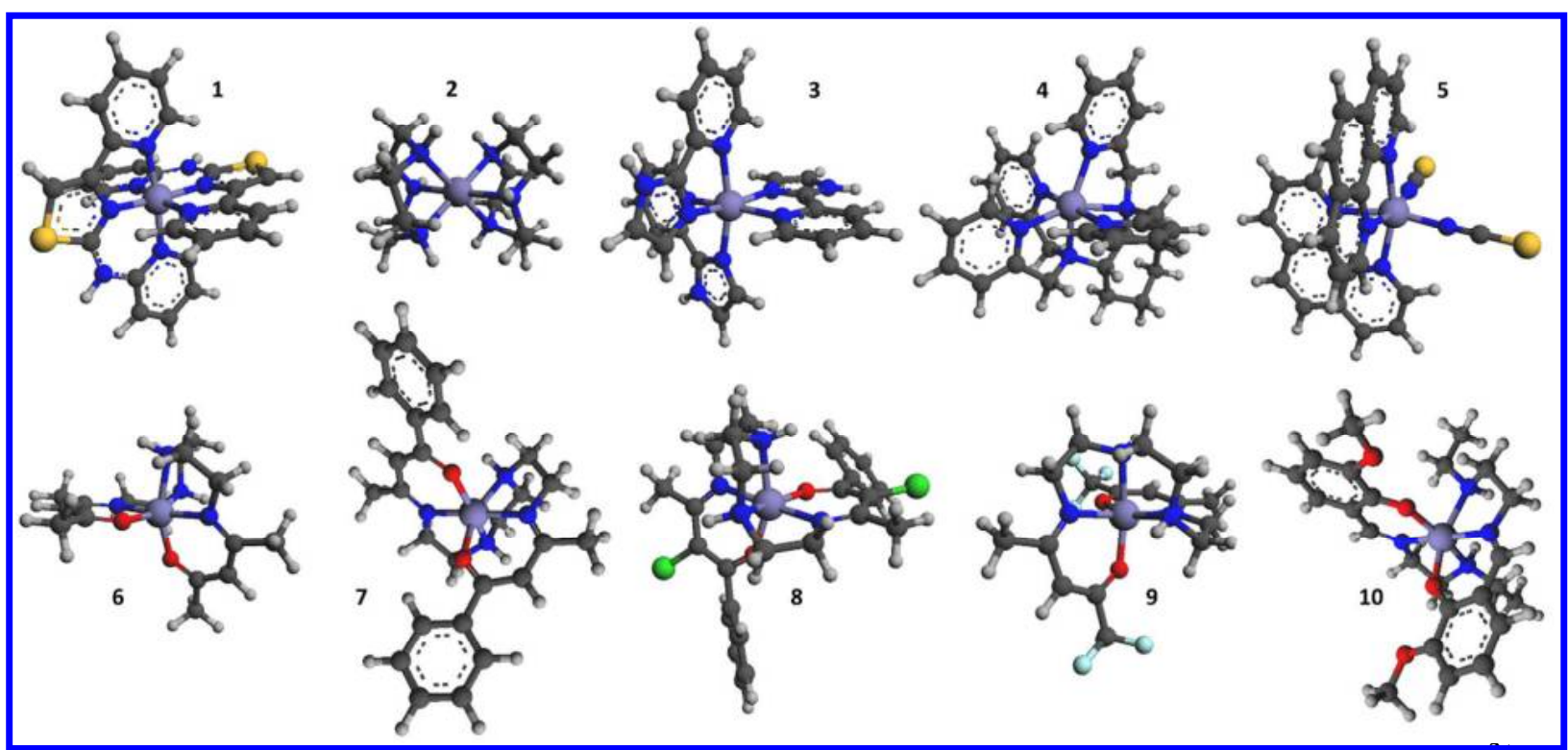

Figure 1. SCO complexes studied in this work: Fe(II) SCO systems: 1: $[\text { Fe(papth)2 }]^{2}$, 2: $\left[\mathrm{Fe}(\operatorname{tacn})_{2}\right]^{2+}$, 3: $\left[\mathrm{Fe}(\text { pyimH })_{3}\right]^{2+}, 4$ : $[\mathrm{Fe}(\operatorname{tpchxn})]^{2+}$, and 5: $\left[\mathrm{Fe}(\text { phen })_{2}(\mathrm{NCS})_{2}\right]$. Iron(III) SCO systems: 6: $\left[\mathrm{Fe}(\mathrm{acac})_{2} \text { trien }\right]^{+}, \mathbf{7}:\left[\mathrm{Fe}(\mathrm{bzac})_{2} \text { trien }\right]^{+}, \mathbf{8}:\left[\mathrm{Fe}(\mathrm{bzacCl})_{2} \text { trien }\right]^{+}, \mathbf{9 :} \mathrm{Fe}(\mathrm{tfac})_{2}$ trien $]^{+}$, and 10: $\left[\mathrm{Fe}(3-\mathrm{MeO}-\mathrm{salenEt})_{2}\right.$.

Furthermore, we used the xcfun library implemented in Turbomole to develop customized functionals $^{83}$ that we studied systematically as well: OPBE-15 (with 15\% HF exchange); rPBE-10 (rPBE customized as a 10\% hybrid); B97-15 (B97-D customized as a 15\% hybrid); CAMB3LYP-15 and CAMB3LYP-17 which have reduced HF exchange relative to the native functional (which has $19 \% \mathrm{HF}$ exchange); and customized versions of $\mathrm{PBE}^{77}$ with 15 , 12, and 10\% HF exchange (PBE0-15, PBE0-12, PBE0-10). The goal was to use a wide range of different types of functionals (GGA, meta, GGA hybrid, meta hybrid, double-hybrid), and then optimize HF exchange toward best performance. Most of these functionals have not been studied before in the context of SCO. 
Dispersion interactions have been shown to affect the SCO equilibrium by selectively favoring the more compact LS state ${ }^{84}$. Accordingly all energy calculations included dispersion corrections using Grimme's D3 method $^{71}$. Some of the methods already include dispersion effects (e.g. the MP2-corrected double hybrid B2PLYP and B97-D) and these were evaluated based on their own dispersion corrections. Methods that do not include any correlation or empirical dispersion correction were corrected by their parameterized version of D-3 (each functional has a specific D3 set of parameters). Some functionals, including all the customized ones, do not have parameterized dispersion corrections and for these, we used an average correction based on previous work (averaged over BHLYP, PBE0, B3LYP, PW6B95, B3LYP* (using the same correction as B3LYP), TPSSh, TPSS, BLYP, PBE, and BP86. These corrections were in $\mathrm{kJ} / \mathrm{mol} 8.3$ (3.8) for $\mathbf{1}, 3.8$ (2.2) for $\mathbf{2}, 12.8(6.1)$ for $\mathbf{3}, 12.3(5.7)$ for $\mathbf{4}, 5.2$ (2.5) for $\mathbf{5}, 0.2$ $(0.5)$ for $\mathbf{6}, 1.4(0.9)$ for $7,9.9(4.6)$ for $\mathbf{8}, 0.4(0.5)$ for $\mathbf{9}$, and $6.2(2.7)$ for $\mathbf{1 0}$. The numbers in parenthesis are standard deviations calculated from the corrections for the different functionals. Because these are differential corrections for HS and LS states, they have relatively small standard deviations. Thus, for SCO using any reasonable dispersion D3 correction is acceptable within an expected uncertainty of $3 \mathrm{~kJ} / \mathrm{mol}$ (the average standard deviation), which is substantially below the target accuracy of $10 \mathrm{~kJ} / \mathrm{mol}$. Notice also the generally smaller values for iron(III) systems.

The thermodynamic and zero-point energy corrections to the energies obtained from numerical frequency calculations in Cosmo were included subsequently to the energy calculation, using the corrections for each individual system as previously described ${ }^{12}$. These corrections are important to correct for before assessing the ability of a functional in predicting the experimental enthalpy of SCO as the experimental numbers includes these effects. 
All the electronic energies are listed in Supporting Information, Table S1 for Fe(II) systems and Table S2 for Fe(III) systems. Table S3 and Table S4 show the corresponding HSLS energy gaps for $\mathrm{Fe}(\mathrm{II})$ and $\mathrm{Fe}(\mathrm{III})$ systems, respectively, corrected for ZPE, relativistic effects, and dispersion. Table $\mathbf{S 5}$ shows the experimental data, with references and error bars, as well as the computed corrections to the direct electronic energy. The experimental errors are within $1 \mathrm{~kJ} / \mathrm{mol}$ for all ten systems studied here; thus the performance of the methods that we identify is not dependent on uncertainties in the reported experimental numbers. Errors vs. experimental data are summarized in Tables S6-S9, and the $\mathrm{Fe}(\mathrm{II})-\mathrm{Fe}(\mathrm{III})$ bias is tabulated in Table S10. Table S11 shows the optimized xyz coordinates of all systems in both HS and LS states.

\section{Results and Discussion.}

General Accuracy of DFT for iron SCO. Figure 2 shows $\Delta H_{\mathrm{SCO}}$ for the five Fe(II) systems computed with the various functionals, and Figure 3 shows $\Delta H_{\mathrm{SCO}}$ for the Fe(III)

systems. As expected from previous work ${ }^{12,31-33}$, the functionals perform quite distinctly, and many favor either the HS or LS state by a large margin. As also expected, the amount of HFexchange included significantly impacts the results. Taking CAMB3LYP as an example, the calculated spin gap decreases by approximate $9 \mathrm{~kJ} / \mathrm{mol}$ for each $2 \% \mathrm{HF}$-exchange included in the calculations.

Because many of these functionals were customized to achieve good accuracy, many perform reasonably well compared to what one would see in a test of "random" functionals, i.e. many functionals in the center of Figure 2 and Figure 3 produce $\Delta H_{\mathrm{SCO}}$ that are close to SCO 
(i.e. slightly positive). However, there are also examples of extremely LS-biased non-hybrid functionals (KT1, KT2, TPSS, M06L, PW91-PW91), and functionals that are extremely HSbiased (M06-2X, M06, PBEH-3C). These functionals are importantly the same for both the $\mathrm{Fe}(\mathrm{II})$ and the $\mathrm{Fe}(\mathrm{III})$ systems, and errors can exceed $100 \mathrm{~kJ} / \mathrm{mol}$.

Figure 4 shows the means signed error (MSE, in black) in the computed $\Delta H_{\mathrm{SCO}}$ vs. experimental data for all ten systems, once the electronic energies of the HS and LS states have been corrected for zero-point energy, dispersion effects, and relativistic contributions; the zeropoint energy generally favors the HS state with the longer and weaker metal-ligand bonds, whereas the relativistic and dispersion effects favor the more compact LS state; these effects have been described in detail previously ${ }^{12}$. The errors are shown in Table S10. The most accurate functionals in terms of systematic HS-LS balance, measured as the MSE for the full data set, are OPBE, the customized CAMB3LYP-15 and CAMB3LYP-17, B97-15 and B3LYP*. Other accurate functionals are CAMB3LYP in its normal form. The most accurate functionals measured by MAE $<10 \mathrm{~kJ} / \mathrm{mol}$ are CAMB3LYP-17, B3LYP*, and B97-15 with 15-17\% HF exchange, closely followed by CAMB3LYP and CAMB3LYP-15, OPBE, rPBE-10, and B3P8615 with MAEs $<15 \mathrm{~kJ} / \mathrm{mol}$. These results show that customized HF exchange fractions remedy the spin balanced for a wide range of functionals. It is interesting to see that the GGA functional OPBE performs so well across the data series without any use of HF exchange; thus the $\mathrm{O}$ exchange functional has an effect that, from the spin state point of view, corresponds to the effect of $\sim 15 \%$ HF exchange. This conclusion supports previous findings by Swart $^{32,85}$ who used OPBE as a basis for his functionals. It is also encouraging to see the excellent performance of CAMB3LYP even in its normal 19\% HF exchange form, but in particular in the customized versions with slightly less HF exchange. If one is not able to use customized versions of functionals, functionals such as OPBE, B3LYP*, and CAMB3LYP are among the most accurate 
for iron SCO; B3LYP* was developed for this purpose ${ }^{42}$ and found in the most elaborate benchmark so far to perform well ${ }^{12}$.

The observation that $\mathrm{rPBE}$ requires only $10 \% \mathrm{HF}$ exchange to reach its maximal accuracy is interesting in the context that $\mathrm{rPBE}$ was developed to reduce the overbinding tendency of $\mathrm{PBE}^{79}$, and we have argued previously ${ }^{9}$ that the overbinding tendency (measured as too strong metal-ligand bonds) and LS bias come together, partly because the HF exchange works to both weaken bonds (by favoring the open-shell dissociated states with more exchange integrals) and favor HS states (which also have more exchange integrals). The behavior of rPBE provides a relevant example of this relationship.

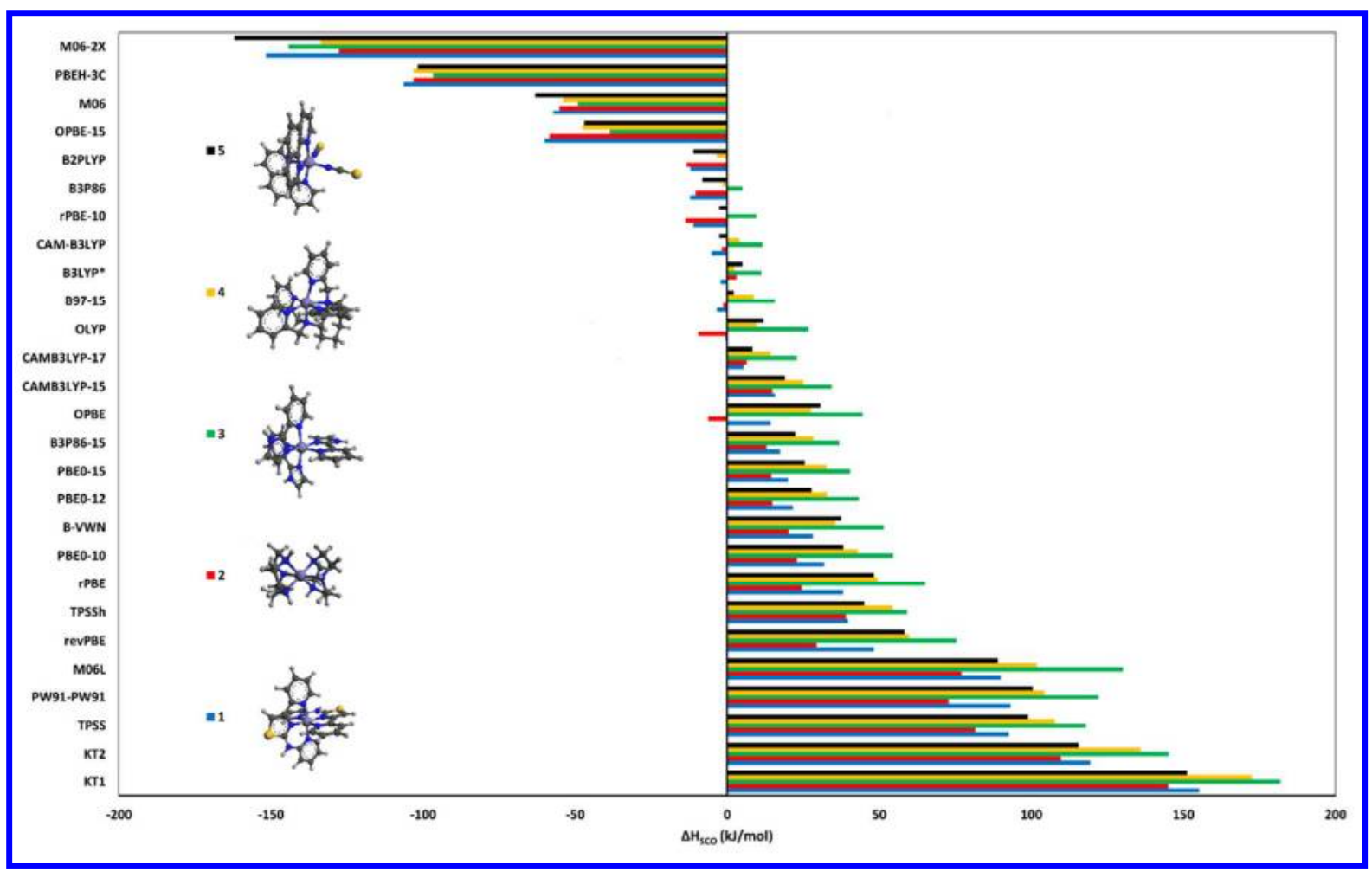

Figure 2. Enthalpies of $\mathrm{SCO}$ in iron(II) systems $\left(\Delta \mathrm{H}_{\mathrm{SCO}}\right.$, in $\left.\mathrm{kJ} / \mathrm{mol}\right)$, computed as the energy difference between HS and LS states, including differential zero-point energy, relativistic, and 
thermal energy corrections, and D3 from B3LYP-D3 if dispersion is not already included in the method.

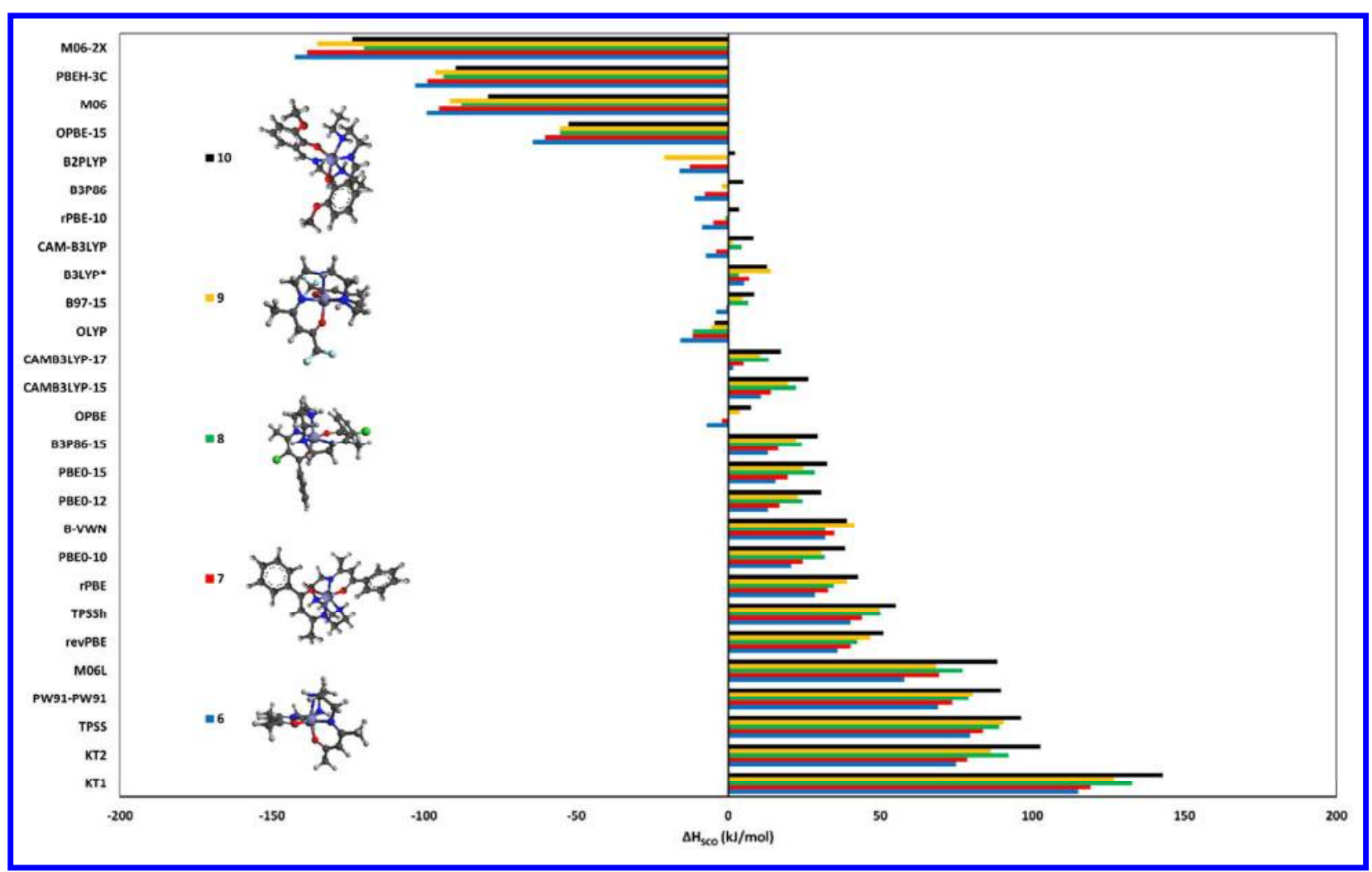

Figure 3. Enthalpies of $\mathrm{SCO}$ in iron(III) systems $\left(\Delta \mathrm{H}_{\mathrm{SCO}}\right.$, in $\left.\mathrm{kJ} / \mathrm{mol}\right)$, computed as the energy difference between HS and LS states, including differential zero-point energy, relativistic, and thermal energy corrections, and D3 from B3LYP-D3 if dispersion is not already included in the method.

Fe(II)-Fe(III) Bias. In addition to the MSE of each functional, Figure 4 also shows the $\mathrm{Fe}(\mathrm{II})-\mathrm{Fe}(\mathrm{III})$ bias, calculated as the MSE of the Fe(II) systems minus the MSE of the Fe(III) systems (red line). This property estimates the balance (transferability) of DFT, which should be a central focus in the search for universal functionals: It is not enough to show a small total MSE, or small total MAE, errors also need to be evenly distributed between the important 
categories of systems likely to be of interest. It is notable from Figure 4 that the $\mathrm{Fe}(\mathrm{II})-\mathrm{Fe}(\mathrm{III})$ bias can reach $20 \mathrm{~kJ} / \mathrm{mol}$ for these systems and easily surpasses $10 \mathrm{~kJ} / \mathrm{mol}$ in many of the good functionals. Upon inspection of the data, such a tendency is also evident from the larger $30 \mathrm{SCOFe}$ data set studied previously ${ }^{12}$, i.e. it is not an artifact of data set or experimental errors, which amount to $1 \mathrm{~kJ} / \mathrm{mol}$ or less (see Table S5). Unfortunately, most accurate functionals perform distinctly different for $\mathrm{Fe}(\mathrm{II})$ and $\mathrm{Fe}(\mathrm{III})$ systems, measured as a non-negligible $\mathrm{Fe}(\mathrm{II})$ Fe(III) bias in Figure 4. The non-hybrid functionals tend to have a positive bias (i.e. they artificially favor LS too much in the Fe(II) compared to Fe(III) systems), whereas the hybrids tend to have a negative bias (they favor HS too much in Fe(II) compared to Fe(III) systems). This general tendency confirms that the effect is real. Unfortunately, most of the functionals that produce a low $\mathrm{Fe}(\mathrm{II})-\mathrm{Fe}(\mathrm{III})$ bias perform relatively poorly for the overall $\Delta H_{\mathrm{SCO}}$. The six functionals that have a numerical Fe(II)-Fe(III) bias $<5 \mathrm{~kJ} / \mathrm{mol}$ are OPBE-15, PBE0-12, PBE010, rPBE, revPBE, and TPSS. Of these, only PBE0-12 has an acceptable MAE of $\sim 15 \mathrm{~kJ} / \mathrm{mol}$, the remaining five functionals having MAEs of $22-82 \mathrm{~kJ} / \mathrm{mol}$.

The most important example is the B3LYP* functional $^{30}$ which is much studied and probably a first pick for many applications of iron chemistry. Its $\mathrm{Fe}(\mathrm{II})-\mathrm{Fe}(\mathrm{III})$ bias is $-15 \mathrm{~kJ} / \mathrm{mol}$ for this data set, and a similar large bias is evident upon reinspection of previous work ${ }^{12}$, i.e. this is a general feature. Since many applications involve the study of $\mathrm{Fe}(\mathrm{II})$ and $\mathrm{Fe}(\mathrm{III})$ in combination, either in separate systems or in actual redox processes (and even when the formal oxidation state does not change but back bonding is involved in Fe(II), e.g. heme systems) this bias will cause an imbalanced treatment of Fe(II) and Fe(III) states by DFT. An imbalance of 15 $\mathrm{kJ} / \mathrm{mol}$ in such a process is not a small error, but has so far never been investigated (until this work) and is a typical example of the importance of balanced performance vs. average performance. 
It is interesting to note that many functionals that have a low $\mathrm{Fe}(\mathrm{II})-\mathrm{Fe}(\mathrm{III})$ bias include the PBE correlation functional, which is largely nonempirical ${ }^{77}$; this could support the notion that more non-empirical functionals are more transferable (or, in some terminology, more "universal"), i.e. it may have exact bounds that partly remedy the $\mathrm{Fe}(\mathrm{II})-\mathrm{Fe}(\mathrm{III})$ bias.

Considering this, the number of good functionals is reduced substantially. As mentioned, B3LYP* is no longer very suitable if the oxidation state can vary at the iron center. We also find that the CAMB3LYP range-corrected hybrid functional produces a bias of $-10 \mathrm{~kJ} / \mathrm{mol}$, whereas the non-hybrid GGA OPBE, on the other hand, has a Fe(II)-Fe(III) bias of $+11 \mathrm{~kJ} / \mathrm{mol}$. One possible solution could be to predict SCO behavior using a combination of the proposed functionals; both OPBE and CAMB3LYP-17 performed exceptionally well on the entire data set, and the individual biases of the two functionals cancel to produce results that compare well with both the overall data set, and the Fe(II) and Fe(III) species separately. However, for normal studies in iron-based catalysis and chemistry, users will have to pick a functional either considering minimal bias with decent accuracy (PBE0-12 being the recommended functional with a bias of $5 \mathrm{~kJ} / \mathrm{mol}$ and MAE of $15 \mathrm{~kJ} / \mathrm{mol}$ ), or, if only one oxidation state of iron is consistently studied, the best functional for the oxidation state of interest, e.g. B3LYP*, CAMB3LYP, or OPBE for Fe(III) and CAMB3LYP-15, CAMB3LYP-17, or B3P86-15 for $\mathrm{Fe}(\mathrm{II})$.

System Dependencies and Pathologies. To investigate whether any of the conclusions above are sensitive to the choice of data set, i.e. if there are pathological cases among the systems that could give rise to erroneous conclusions, we divided errors into system as shown in a radar plot in Figure 5A. The blue range represents the MAE for each of the systems, using data for all functionals in the study, whereas the red range represents the system-specific MAEs for the most accurate functionals (those with $\mathrm{MAE}<15 \mathrm{~kJ} / \mathrm{mol}$ for the full data set). We recommend 
using radar plots of this type to identify unsuitable (pathological) systems in a benchmark data set: A healthy data set will have an almost circular form of both curves, as is indeed seen in Figure 5A; thus, our data set does not include pathological systems.

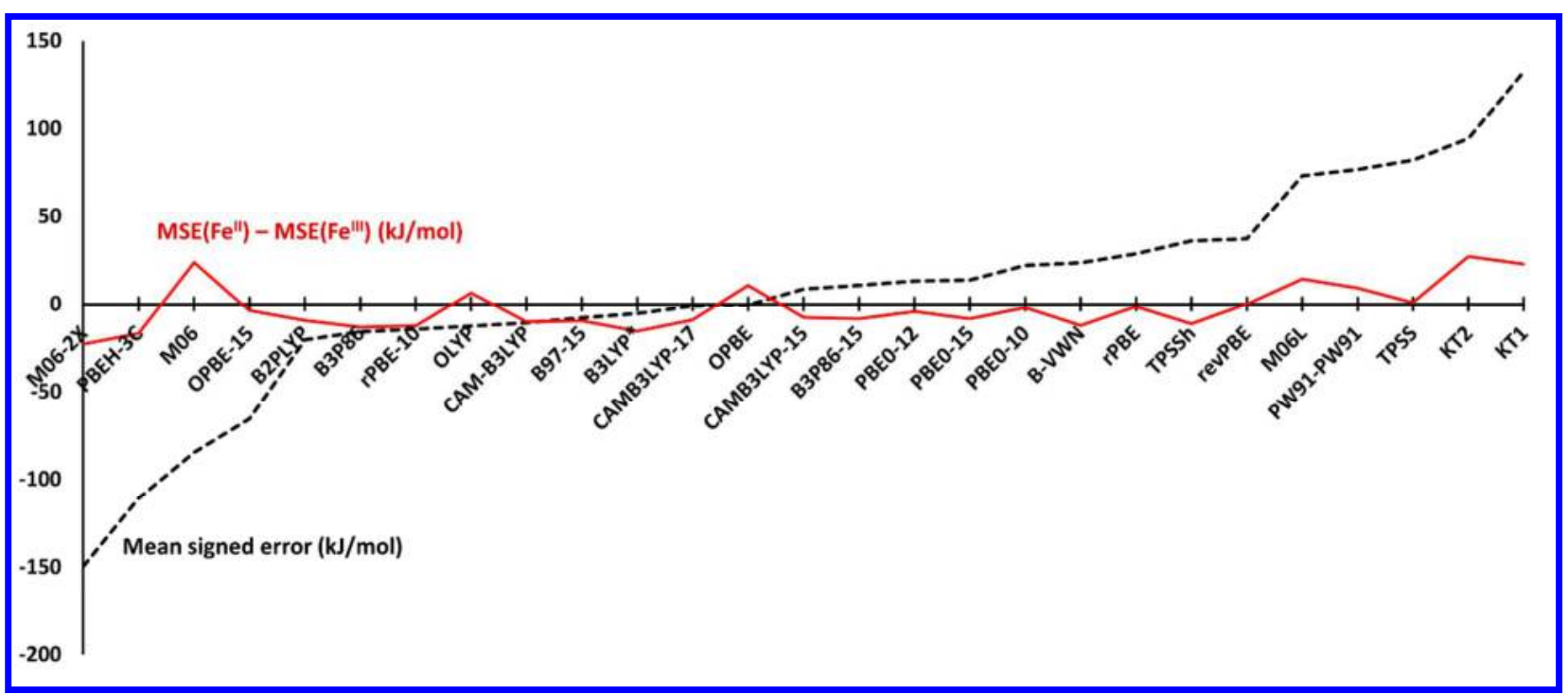

Figure 4. Mean signed error (kJ/mol, black) and the Fe(II)-Fe(III) bias, calculated as the difference in mean signed error for the $\mathrm{Fe}(\mathrm{II})$ and $\mathrm{Fe}(\mathrm{III})$ systems $(\mathrm{kJ} / \mathrm{mol}$, red).

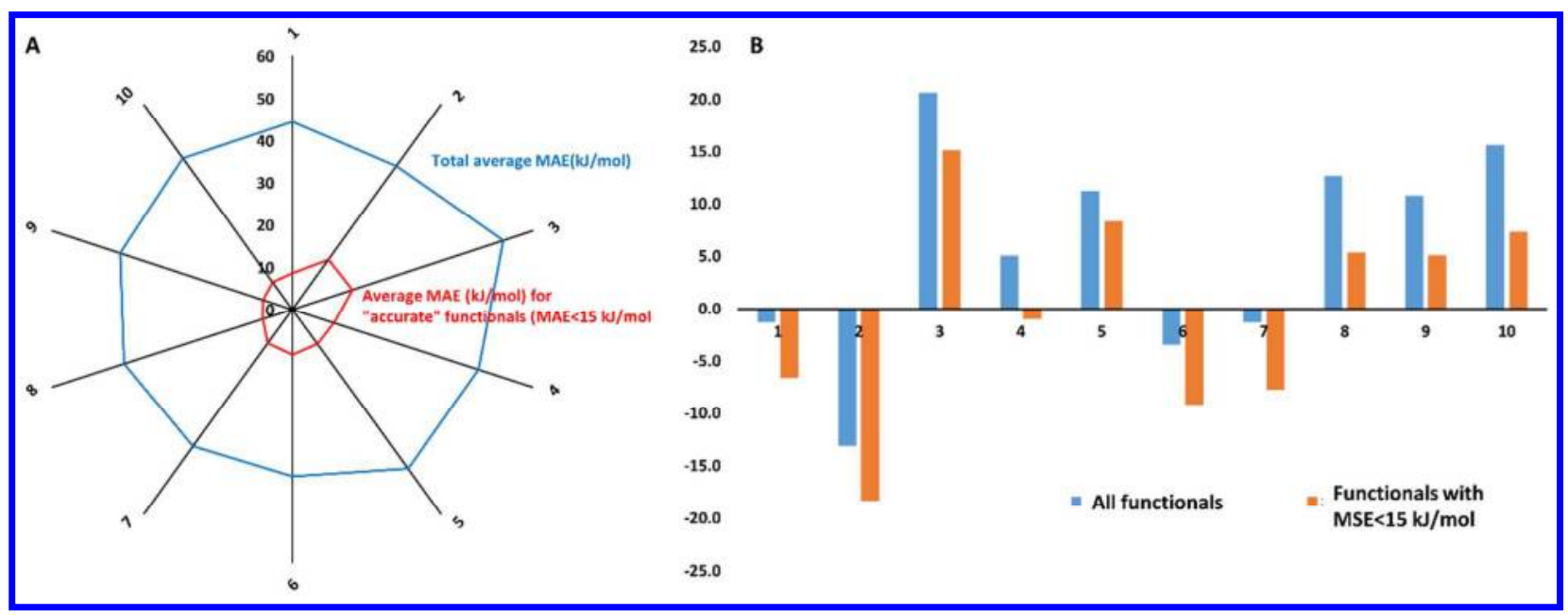


Figure 5. A) System-specific mean absolute error $(\mathrm{kJ} / \mathrm{mol})$ of all functionals (blue) vs. best functionals (red) divided into system. B) Mean signed error $(\mathrm{kJ} / \mathrm{mol})$ for each system used in the test set, averaged over all functionals (blue) and those functionals that have MSE $<15 \mathrm{~kJ} / \mathrm{mol}$.

Another important point is the magnitude of systematic errors divided into system type, because they can reflect missing realism in the model of that system; such as the plot is shown in Figure 5B. The blue bars represent the MSE for all studied functionals for a given system, whereas the orange bars represent the MSE of each system using only accurate functionals (with MSE $<15 \mathrm{~kJ} / \mathrm{mol}$ ). Systems 2 and 3 have errors up to $15-20 \mathrm{~kJ} / \mathrm{mol}$ that could reflect either a weakness in the realism of the chemical model used to compute $\Delta \mathrm{H}_{\mathrm{SCO}}$ (e.g. neglect of counter ions) or a general weakness in the DFT treatment (dispersion, steric or electronic strain or similar). These two are both Fe(II) systems, but the errors are otherwise well distributed for both $\mathrm{Fe}(\mathrm{II})$ and $\mathrm{Fe}(\mathrm{III})$ systems.

Precision vs. Accuracy of DFT Applied to Iron Spin States. The final thing we wanted to investigate was whether the errors that we observed above are distributed in a consistent way or whether they spread, i.e. if there is a predictable error associated with each functional. We decided to quantify the precision of the functional by the standard deviation of the errors: The larger this value is, the less predictive are the errors obtainable with a functional. We also wanted to see if the precision correlates with the accuracy of the density functionals. Precision is arguably a very important (but overlooked) aspect of performance, because an apparently accurate functional could obtain its good average performance with a large spread in performance for the individual system, which would make the performance of the functional unpredictable. To study this, we suggest to use scatter plots of the type shown in Figure 6A (for 
$\mathrm{Fe}(\mathrm{II})$ systems) and Figure 6B (for Fe(III) systems), where precision (as defined above) is plotted vs. accuracy.

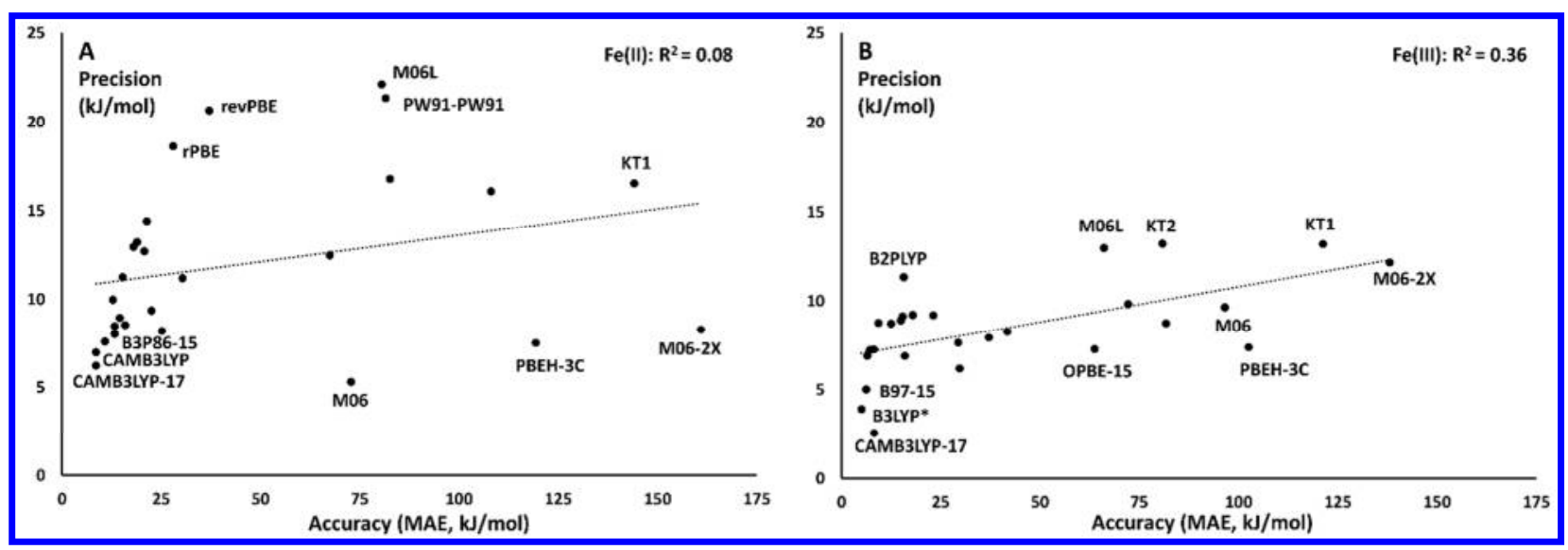

Figure 6. Precision vs. accuracy of density functionals for spin crossover: A) Fe(II) systems; B) $\mathrm{Fe}(\mathrm{III})$ systems.

It is evident from the analysis in Figure 6 that the $\mathrm{Fe}(\mathrm{II})$ and $\mathrm{Fe}(\mathrm{III})$ systems behave distinctly, which confirms the importance of studying $\mathrm{Fe}(\mathrm{II})-\mathrm{Fe}(\mathrm{III})$ balance. Also important is the observation that precision is weakly correlated to accuracy, with decent correlation for Fe(III) systems $\left(\mathrm{R}^{2} \sim 0.36\right)$ but not for $\mathrm{Fe}(\mathrm{II})$ systems $\left(\mathrm{R}^{2} \sim 0.08\right)$. Thus, some functionals that are quite accurate as measured by the standard approach of computed MAE, turn out to be very imprecise. The analysis of the accuracy-precision relationship is quite interesting and we are not aware that it has been discussed in detail. Thus, we see for example that the accurate hybrid functionals with $15-17 \%$ HF exchange are consistently also the most precise functionals (with precisions of the order of $5 \mathrm{~kJ} / \mathrm{mol}$ ), which is a very important conclusion because it is required for predictive use of DFT. Importantly, there are functionals that have good accuracy but poor precision, such as rPBE and B2PLYP. In addition there are very inaccurate functionals with high precision, the most prominent examples being PBE-H3C, M06, and M06-2X, as well as functionals that are 
both inaccurate and imprecise, such as M06L and KT1. Thus, all four types of functional behavior (accurate/precise, accurate/imprecise, inaccurate/precise, inaccurate/imprecise) are observed, which should be of some interest in the future consideration of these and other functionals.

\section{Conclusions.}

This work has studied the description of the HS and LS states of well-known SCO systems containg $\mathrm{Fe}(\mathrm{II})$ and $\mathrm{Fe}(\mathrm{III})$, and compared DFT-derived enthalpeis against available experimental data. It is shown that $\mathrm{Fe}(\mathrm{II})$ and $\mathrm{Fe}(\mathrm{III})$ systems are typically not treated in a balanced way by DFT, i.e. a functional is significantly more accurate for one of these oxidation states than the other, and thus cannot distinguish fairly between SCO candidates of both types. To understand this "Fe(II)-Fe(III) bias", we deployed a range of functionals, including customized versions of GGA, hybrid, meta-GGA, meta-hybrid, double-hybrid, and long-range-corrected hybrid functionals, to search for the best-possible description of this problem by modern DFT.

We find that most functionals, regardless of the nature of the correlation and exchange functionals, become more accurate in their hybrid forms once the included HF exchange is adjusted to $10-17 \%$. The most accurate functionals measured as mean absolute errors $<10$ $\mathrm{kJ} / \mathrm{mol}$ are CAMB3LYP-17, B3LYP*, and B97-15 with 15-17\% HF exchange, closely followed by CAMB3LYP and CAMB3LYP-15, OPBE, rPBE-10, and B3P86-15. The highest possible accuracy however comes with a clear Fe(II)-Fe(III) bias of up to $\sim 20 \mathrm{~kJ} / \mathrm{mol}$. Hybrid functionals, regardless of design (including B2PLYP double hybrids and meta hybrids) tend to favor HS too much in $\mathrm{Fe}(\mathrm{II})$ vs. Fe(III), which is important in many studies of iron spin states where the oxidation state of iron can vary, e.g. rational SCO design and studies of catalytic processes 
involving iron. The bias tends to grow with the amount of HF exchange such that for BHLYP the imbalance amounts to $39 \mathrm{~kJ} / \mathrm{mol}$ and for TPSSh it is $21 \mathrm{~kJ} / \mathrm{mol}$. In contrast, GGA functionals display a small $\mathrm{Fe}(\mathrm{II})-\mathrm{Fe}(\mathrm{III})$ bias, but are generally inaccurate, except those using the $\mathrm{O}$ exchange functional.

Upon detailed analysis of both accuracy, precision, and balanced treatment (system bias), we find that the only functional with a combined bias $<5 \mathrm{~kJ} / \mathrm{mol}$ and a decent MAE $(15 \mathrm{~kJ} / \mathrm{mol})$ is the customized PBE0-12 functional. Alternatively, one has to either sacrifice Fe(II)-Fe(III) balance, use the best functionals for each oxidation state separately, or use a combination of functionals to directly estimate the SCO energetics.

The precision (measured as the standard deviation of errors) is not generally strongly correlated to accuracy (measured by the MAE) of a functional, which is problematic because it makes DFT less predictive regardless of a low MAE. Importantly, all four types of functional behavior (accurate/precise, accurate/imprecise, inaccurate/precise, inaccurate/imprecise) are observed. Thus, our work illustrates the importance of balanced accuracy for systems likely to occur in context during a process.

In many catalytic processes both the oxidation and the spin state of iron changes, the most prominent example perhaps being heme chemistry. In such cases, the Fe(II)-Fe(III) bias will cause an error up to $20 \mathrm{~kJ} / \mathrm{mol}$ in the potential energy surfaces that will not be removed by error cancellation. In this context, our work also presents the first benchmark of the rPBE functional widely used in iron-based catalysis such as the Haber-Bosch process, where iron spin and oxidation states may change. The rPBE functional provides a much better LS-HS balance and is less baised toward LS than PBE, but is also very imprecise, which may constitute a problem for predictive use of DFT in catalysis when spin and oxidation states change. The 
analysis provided in this work should be of value in establishing more accurate models of catalytic processes of this type that take into account the $\mathrm{Fe}(\mathrm{II})-\mathrm{Fe}(\mathrm{III})$ bias, accuracy, and precision in a combined way.

Supporting Information available. The Supporting information file contains details of the computations performed in this work, including all electronic energies, derived high-spin lowspin gaps, experimental data used, ZPE and relativistic corrections, and coordinates of all studied systems in both HS and LS states. This material is available free of charge via the Internet at http://pubs.acs.org.

Acknowledgements. The authors acknowledge DTU for use of the Steno computer Cluster, which was originally established by a grant to KPK from The Danish Council for Independent Research | Natural sciences (FNU), grant 272-08-0041 (National Young Elite Researcher Prize).

\section{References.}

(1) Halcrow, M. A. Spin-Crossover Materials: Properties and Applications; John Wiley \& Sons, 2013.

(2) Gütlich, P.; Goodwin, H. A. Spin Crossover-an Overall Perspective. In Spin Crossover in Transition Metal Compounds I; Springer, 2004; pp 1-47.

(3) Létard, J.-F.; Guionneau, P.; Goux-Capes, L. Towards Spin Crossover Applications. Spin Crossover Transit. Met. Compd. III 2004, 1-19. 
(4) Brooker, S. Spin Crossover with Thermal Hysteresis: Practicalities and Lessons Learnt. Chem.Soc.Rev. 2015, 44 (10), 2880-2892.

(5) Gütlich, P.; Garcia, Y.; Goodwin, H. A. Spin Crossover Phenomena in Fe(II) Complexes. Chem.Soc.Rev. 2000, 29 (6), 419-427.

(6) Harding, D. J.; Harding, P.; Phonsri, W. Spin Crossover in Iron (III) Complexes. Coord. Chem. Rev. 2016, 313, 38-61.

(7) Guionneau, P. Crystallography and Spin-Crossover. A View of Breathing Materials. Dalt. Trans. 2014, 43 (2), 382-393.

(8) Ruiz, E. Charge Transport Properties of Spin Crossover Systems. Phys. Chem. Chem. Phys. 2014, 16 (1), 14-22.

(9) Kepp, K. P. Consistent Descriptions of Metal-ligand Bonds and Spin-Crossover in Inorganic Chemistry. Coord. Chem. Rev. 2013, 257 (1), 196-209.

(10) Toftlund, H. Spin Equilibrium in Solutions. Monatshefte für Chemie/Chemical Mon. 2001, $132(11), 1269-1277$.

(11) Kershaw Cook, L. J.; Kulmaczewski, R.; Mohammed, R.; Dudley, S.; Barrett, S. A.; Little, M. A.; Deeth, R. J.; Halcrow, M. A. A Unified Treatment of the Relationship between Ligand Substituents and Spin State in a Family of Iron (II) Complexes. Angew. Chemie Int.Ed. 2016, 55 (13), 4327-4331.

(12) Kepp, K. P. Theoretical Study of Spin Crossover in 30 Iron Complexes. Inorg. Chem. 2016, 55 (6), 2717-2727.

(13) Paulsen, H.; Duelund, L.; Winkler, H.; Toftlund, H.; Trautwein, A. X. Free Energy of 
Spin-Crossover Complexes Calculated with Density Functional Methods. Inorg. Chem. 2001, 40 (9), 2201-2203.

(14) Paulsen, H.; Schünemann, V.; Wolny, J. A. Progress in Electronic Structure Calculations on Spin $\square$ Crossover Complexes. Eur.J.Jnorg Chem. 2013, 2013 (5 $\square 6$ ), 628-641.

(15) Scheidt, W. R.; Reed, C. A. Spin-State/stereochemical Relationships in Iron Porphyrins: Implications for the Hemoproteins. Chem.Rev. 1981, 81 (6), 543-555.

(16) Jensen, K. P.; Ryde, U. How O2 Binds to Heme: Reasons for Rapid Binding and Spin Inversion. L. Biol. Chem. 2004, 279 (15), 14561-14569.

(17) Harvey, J. N.; Poli, R.; Smith, K. M. Understanding the Reactivity of Transition Metal Complexes Involving Multiple Spin States. Coord. Chem. Rev. 2003, 238, 347-361.

(18) Sorai, M.; Nakano, M.; Miyazaki, Y. Calorimetric Investigation of Phase Transitions Occurring in Molecule-Based Magnets. Chem.Rev. 2006, 106 (3), 976-1031.

(19) Molnár, G.; Salmon, L.; Nicolazzi, W.; Terki, F.; Bousseksou, A. Emerging Properties and Applications of Spin Crossover Nanomaterials. L.Mater. Chem C 2014, 2 (8), 13601366.

(20) Liu, T.; Zheng, H.; Kang, S.; Shiota, Y.; Hayami, S.; Mito, M.; Sato, O.; Yoshizawa, K.; Kanegawa, S.; Duan, C. A Light-Induced Spin Crossover Actuated Single-Chain Magnet. Nat. Commun. 2013, 4, 2826.

(21) Cirera, J.; Ruiz, E. Theoretical Modeling of Two-Step Spin-Crossover Transitions in Fe II Dinuclear Systems. L.Mater. Chem.C 2015, 3 (30), 7954-7961.

(22) Jørgensen, C. K. Electron Transfer Spectra of Hexahalide Complexes. Mol. Phys. 1959, 2 
(3), 309-332.

(23) Tsuchida, R. Absorption Spectra of Co-Ordination Compounds. I. Bull. Chem. Soc. Jpn. 1938, $13(5), 388-400$.

(24) Shimura, Y.; Tsuchida, R. Absorption Spectra of Co(III) Complexes. II. Redetermination of the Spectrochemical Series. Bull. Chem.Soc.Jon. 1956, 29 (3), 311-316.

(25) Fajans, K. Struktur und Deformation Der Elektronenhüllen in Ihrer Bedeutung für Die Chemischen und Optischen Eigenschaften Anorganischer Verbindungen. Naturwissenschaften 1923, 11 (10), 165-172.

(26) Mortensen, S. R.; Kepp, K. P. Spin Propensities of Octahedral Complexes From Density Functional Theory. L.Phvs. Chem.A 2015, 119, 4041-4050.

(27) Kepp, K. P. Heme: From Quantum Spin Crossover to Oxygen Manager of Life. Coord. Chem. Rev. 2017, 344, 363-374.

(28) Kohn, W.; Becke, A. D.; Parr, R. G. Density Functional Theory of Electronic Structure. J. Phvs. Chem. 1996, 100 (31), 12974-12980.

(29) Becke, A. D. Perspective: Fifty Years of Density-Functional Theory in Chemical Physics. L. Chem. Phys. 2014, 140 (18), 18 A301.

(30) Salomon, O.; Reiher, M.; Hess, B. A. Assertion and Validation of the Performance of the B3LYP $\square$ Functional for the First Transition Metal Row and the G2 Test Set. J. Chem. Phys. 2002, 117 (10), 4729-4737.

(31) Reiher, M. Theoretical Study of the Fe (Phen $)_{2}(\mathrm{NCS})_{2}$ Spin-Crossover Complex with Reparametrized Density Functionals. Inorg. Chem. 2002, 41 (25), 6928-6935. 
(32) Swart, M. Accurate Spin-State Energies for Iron Complexes. J. Chem. Theory Comput. 2008, 4 (12), 2057-2066.

(33) Jensen, K. P.; Cirera, J. Accurate Computed Enthalpies of Spin Crossover in Iron and Cobalt Complexes. L.Phvs. Chem.A 2009, 113, 10033-10039.

(34) Isley III, W. C.; Zarra, S.; Carlson, R. K.; Bilbeisi, R. A.; Ronson, T. K.; Nitschke, J. R.; Gagliardi, L.; Cramer, C. J. Predicting Paramagnetic ${ }^{1} \mathrm{H}$ NMR Chemical Shifts and StateEnergy Separations in Spin-Crossover Host-guest Systems. Phys. Chem. Chem. Phys. 2014, 16 (22), 10620-10628.

(35) Ioannidis, E. I.; Kulik, H. J. Towards Quantifying the Role of Exact Exchange in Predictions of Transition Metal Complex Properties. L.Chem. Phvs. 2015, 143 (3), 34104.

(36) Coskun, D.; Jerome, S. V; Friesner, R. A. Evaluation of the Performance of the B3LYP, PBE0, and M06 DFT Functionals, and DBLOC-Corrected Versions, in the Calculation of Redox Potentials and Spin Splittings for Transition Metal Containing Systems. J. Chem. Theorv Comput. 2016, 12 (3), 1121-1128.

(37) Conradie, J.; Ghosh, A. DFT Calculations on the Spin-Crossover Complex Fe(salen)(NO): A Quest for the Best Functional. L.Phys.Chem.B 2007, 111 (44), 12621-12624.

(38) Verma, P.; Varga, Z.; Klein, J. E. M. N.; Cramer, C. J.; Que, L.; Truhlar, D. G. Assessment of Electronic Structure Methods for the Determination of the Ground Spin States of Fe(II), Fe(III) and Fe(IV) Complexes. Phys. Chem. Chem. Phys. 2017, 19 (20), 13049-13069.

(39) Swart, M.; Groenhof, A. R.; Ehlers, A. W.; Lammertsma, K. Validation of Exchange-Correlation Functionals for Spin States of Iron Complexes. J. Phys. Chem. A 
2004, 108 (25), 5479-5483.

(40) Cirera, J.; Ruiz, E. Theoretical Modeling of the Ligand-Tuning Effect over the Transition Temperature in Four-Coordinated FeII Molecules. Inorg. Chem. 2016, 55 (4), 1657-1663.

(41) Houghton, B. J.; Deeth, R. J. Spin $\square$ State Energetics of Fe ${ }^{\text {II }}$ Complexes-The Continuing Voyage Through the Density Functional Minefield. Eur. J. Inorg. Chem. 2014, 2014 (27), $4573-4580$.

(42) Reiher, M.; Salomon, O.; Hess, B. A. Reparameterization of Hybrid Functionals Based on Energy Differences of States of Different Multiplicity. Theor. Chem. Acc. 2001, 107 (1), $48-55$.

(43) Gani, T. Z. H.; Kulik, H. J. Unifying Exchange Sensitivity in Transition-Metal Spin-State Ordering and Catalysis through Bond Valence Metrics. J. Chem. Theory Comput. 2017, $13(11), 5443-5457$.

(44) Ioannidis, E. I.; Kulik, H. J. Ligand-Field-Dependent Behavior of Meta-GGA Exchange in Transition-Metal Complex Spin-State Ordering. J.Phvs. Chem.A 2017, 121 (4), 874-884.

(45) Peverati, R.; Truhlar, D. G. Quest for a Universal Density Functional: The Accuracy of Density Functionals across a Broad Spectrum of Databases in Chemistry and Physics. Philos. Trans. R. Soc.London A Math. Phvs. Eng.Sci. 2014, 372 (2011), 20120476.

(46) Medvedev, M. G.; Bushmarinov, I. S.; Sun, J.; Perdew, J. P.; Lyssenko, K. A. Density Functional Theory Is Straying from the Path toward the Exact Functional. Science 2017, $355(6320), 49-52$.

(47) Kepp, K. P. Comment on "Density Functional Theory Is Straying from the Path toward 
the Exact Functional." Science 2017, 356 (6337), 496-497.

(48) Hughes, T. F.; Friesner, R. A. Correcting Systematic Errors in DFT Spin-Splitting Energetics for Transition Metal Complexes. L.Chem. Theorv Comput. 2011, 7 (1), 19-32.

(49) Ahlrichs, R.; Bär, M.; Häser, M.; Horn, H.; Kölmel, C. Electronic Structure Calculations on Workstation Computers: The Program System Turbomole. Chem. Phys. Lett. 1989, 162 (3), 165-169.

(50) Eichkorn, K.; Treutler, O.; Öhm, H.; Häser, M.; Ahlrichs, R. Auxiliary Basis Sets to Approximate Coulomb Potentials. Chem. Phvs. Lett. 1995, 240 (4), 283-290.

(51) Weigend, F.; Häser, M. RI-MP2: First Derivatives and Global Consistency. Theor. Chem. Acc. 1997, 97 (1), 331-340.

(52) Beattie, J. K.; Binstead, R. A.; West, R. J. Intersystem Crossing Observed by Ultrasonic Relaxation of the Singlet-Quintet Spin Equilibrium of Iron (II) Complexes in Solution. $J$. Am.Chem.Soc. 1978, 100 (10), 3044-3050.

(53) Turner, J. W.; Schultz, F. A. Intramolecular and Environmental Contributions to Electrode Half-Reaction Entropies of $\mathrm{M}(\operatorname{tacn})_{2}{ }^{3+/ 2+}(\mathrm{M}=\mathrm{Fe}, \mathrm{Co}, \mathrm{Ni}, \mathrm{Ru} ; \mathrm{Tacn}=1,4,7-$ Triazacyclononane) Redox Couples. Inorg Chem. 1999, 38 (2), 358-364.

(54) Jesson, J. P.; Trofimenko, S.; Eaton, D. R. Spin Equilibria in Octahedral Iron(II)Poly((1Pyrazolyl)-Borates. J.Am.Chem.Soc. 1967, 89 (13), 3158-3164.

(55) Sorai, M. Calorimetric Investigations of Phase Transitions Occurring in Molecule-Based Materials in Which Electrons Are Directly Involved. Bull. Chem. Soc. Jpn. 2001, 74 (12), $2223-2253$. 
(56) Dose, E. V; Murphy, K. M. M.; Wilson, L. J. Synthesis and Spin-State Studies in Solution Of $\gamma$-Substituted Tris ( $\beta$-Diketonato) Iron (III) Complexes and Their Spin-Equilibrium. $\beta$ Ketoimine Analogues Derived from Triethylenetetramine. Inorg. Chem. 1976, 15 (11), $2622-2630$.

(57) Koikawa, M.; B. Jensen, K.; Matsushima, H.; Tokii, T.; Toftlund, H. Syntheses and Crystal Structures of Divalent Complexes with a New Hexadentate Ligand Derived from 1,4,7-Triazacyclononane. J. Chem. Soc. Dalt. Trans. 1998, No. 7, 1085-1086.

(58) Sorai, M.; Burriel, R.; Westrum, E. F.; Hendrickson, D. N. Mechanochemical Effect in the Iron (III) Spin Crossover Complex [Fe(3-MeO-salenEt) $\left.)_{2}\right] \mathrm{PF}_{6}$ as Studied by Heat Capacity Calorimetry. J.Phys. Chem.B 2008, 112 (14), 4344-4350.

(59) Becke, A. D. Density-Functional Exchange-Energy Approximation with Correct Asymptotic Behavior. Phvs. Rev. A 1988, 38 (6), 3098-3100.

(60) Perdew, J. P. Density-Functional Approximation for the Correlation Energy of the Inhomogeneous Electron Gas. Phvs.Rev.B 1986, 33 (12), 8822-8824.

(61) Weigend, F.; Ahlrichs, R. Balanced Basis Sets of Split Valence, Triple Zeta Valence and Quadruple Zeta Valence Quality for H to Rn: Design and Assessment of Accuracy. Phys. Chem. Chem. Phvs. 2005, 7 (18), 3297-3305.

(62) Schäfer, A.; Klamt, A.; Sattel, D.; Lohrenz, J. C. W.; Eckert, F. COSMO Implementation in TURBOMOLE: Extension of an Efficient Quantum Chemical Code towards Liquid Systems. Phvs. Chem. Chem. Phvs. 2000, 2 (10), 2187-2193.

(63) Klamt, A.; Schüürmann, G. COSMO: A New Approach to Dielectric Screening in Solvents with Explicit Expressions for the Screening Energy and Its Gradient. J. Chem. 
Soc. Perkin Trans. 2 1993, No. 5, 799-805.

(64) Jensen, K. P.; Roos, B. O.; Ryde, U. Performance of Density Functionals for First Row Transition Metal Systems. J.Chem.Phvs. 2007, 126, 14103.

(65) Grimme, S. Semiempirical Hybrid Density Functional with Perturbative Second-Order Correlation. L.Chem. Phvs. 2006, 124 (3), 34108.

(66) Tao, J.; Perdew, J. P.; Staroverov, V. N.; Scuseria, G. E. Climbing the Density Functional Ladder: Nonempirical Meta Generalized Gradient Approximation Designed for Molecules and Solids. Phvs. Rev.Lett. 2003, 91 (14), 146401.

(67) Perdew, J. P.; Tao, J.; Staroverov, V. N.; Scuseria, G. E. Meta-Generalized Gradient Approximation: Explanation of a Realistic Nonempirical Density Functional. J. Chem. Phys. 2004, 120 (15).

(68) Becke, A. D. Density $\square$ functional Thermochemistry. III. The Role of Exact Exchange. J. Chem. Phys. 1993, 98 (7), 5648-5652.

(69) Lee, C.; Yang, W.; Parr, R. G. Development of the Colle-Salvetti Correlation-Energy Formula into a Functional of the Electron Density. Phvs.Rev.B 1988, 37 (2), 785-789.

(70) Stephens, P. J.; Devlin, F. J.; Chabalowski, C. F.; Frisch, M. J. Ab Initio Calculation of Vibrational Absorption and Circular Dichroism Spectra Using Density Functional Force Fields. L.Phvs. Chem. 1994, 98 (45), 11623-11627.

(71) Grimme, S.; Antony, J.; Ehrlich, S.; Krieg, H. A Consistent and Accurate Ab Initio Parametrization of Density Functional Dispersion Correction (DFT-D) for the 94 Elements H-Pu. L.Chem. Phvs. 2010, 132 (15), 154104. 
(72) Yanai, T.; Tew, D. P.; Handy, N. C. A New Hybrid Exchange-correlation Functional Using the Coulomb-Attenuating Method (CAM-B3LYP). Chem. Phvs. Lett. 2004, 393 (1), $51-57$.

(73) Zhao, Y.; Truhlar, D. G. The M06 Suite of Density Functionals for Main Group Thermochemistry, Thermochemical Kinetics, Noncovalent Interactions, Excited States, and Transition Elements: Two New Functionals and Systematic Testing of Four M06Class Functionals and 12 Other Function. Theor. Chem.Acc. 2008, 120 (1-3), 215-241.

(74) Zhao, Y.; Truhlar, D. G. A New Local Density Functional for Main-Group Thermochemistry, Transition Metal Bonding, Thermochemical Kinetics, and Noncovalent Interactions. L.Chem. Phvs. 2006, 125 (19), 194101.

(75) Keal, T. W.; Tozer, D. J. The Exchange-Correlation Potential in Kohn-Sham Nuclear Magnetic Resonance Shielding Calculations. J. Chem. Phvs. 2003, 119 (6), 3015-3024.

(76) Perdew, J. P.; Wang, Y. Accurate and Simple Analytic Representation of the Electron-Gas Correlation Energy. Phvs. Rev. B 1992, 45 (23), 13244.

(77) Perdew, J. P.; Burke, K.; Ernzerhof, M. Generalized Gradient Approximation Made Simple. Phvs. Rev. Lett. 1996, 77 (18), 3865.

(78) Zhang, Y.; Yang, W. Comment on "Generalized Gradient Approximation Made Simple.” Phvs. Rev. Lett. 1998, 80 (4), 890.

(79) Hammer, B.; Hansen, L. B.; Nørskov, J. K. Improved Adsorption Energetics within Density-Functional Theory Using Revised Perdew-Burke-Ernzerhof Functionals. Phys. Rev.B 1999, 59 (11), 7413-7421. 
(80) Handy, N. C.; Cohen, A. J. Left-Right Correlation Energy. Mol.Phvs. 2001, 99 (5), $403-$ 412.

(81) Vosko, S. H.; Wilk, L.; Nusair, M. Accurate Spin-Dependent Electron Liquid Correlation Energies for Local Spin Density Calculations: A Critical Analysis. Can. J. Phys. 1980, 58 (8), 1200-1211.

(82) Grimme, S.; Brandenburg, J. G.; Bannwarth, C.; Hansen, A. Consistent Structures and Interactions by Density Functional Theory with Small Atomic Orbital Basis Sets. J. Chem. Phys. 2015, 143 (5), 54107.

(83) Ekström, U.; Visscher, L.; Bast, R.; Thorvaldsen, A. J.; Ruud, K. Arbitrary-Order Density Functional Response Theory from Automatic Differentiation. J. Chem. Theory Comput. 2010, $6(7), 1971-1980$.

(84) Kepp, K. P. The Ground States of iron(III) Porphines: Role of Entropy-enthalpy Compensation, Fermi Correlation, Dispersion, and Zero-Point Energies. J. Inorg. Biochem. 2011, 105 (10), 1286-1292.

(85) Swart, M.; Solà, M.; Bickelhaupt, F. M. A New All-Round Density Functional Based on Spin States and SN2 Barriers. L.Chem.Phvs. 2009, 131 (9), 94103. 


\section{TOC Graphic}

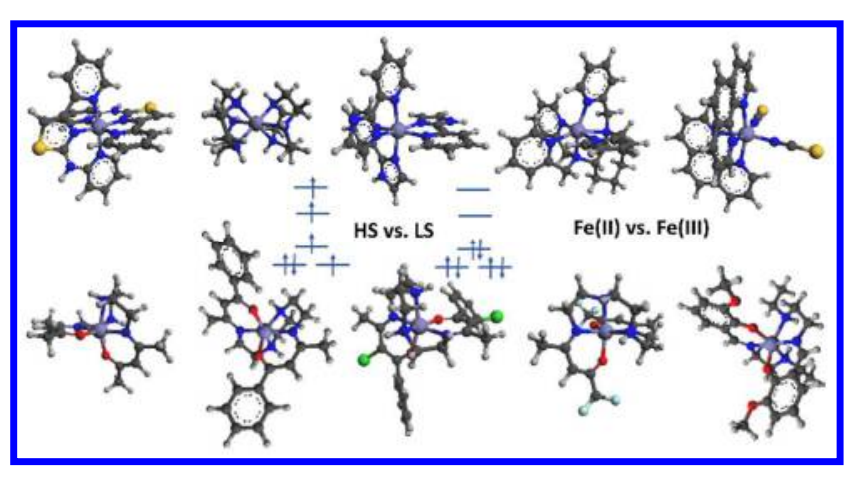

